\title{
DIEP flap salvage by cannula venesection of the superficial inferior epigastric vein
}

\author{
Puttan Wongtriratanachai ${ }^{1}$ - Abbe Michelle Martin ${ }^{2} \cdot$ Kongkrit Chaiyasate $^{3}$
}

Received: 8 June 2015 / Accepted: 20 July 2015 /Published online: 15 January 2016

(C) The Author(s) 2016. This article is published with open access at Springerlink.com

\begin{abstract}
The deep inferior epigastric perforator (DIEP) flap is a technique of autologous breast reconstruction that is gaining popularity. The main advantage of the DIEP flap over the traditional transverse rectus abdominis myocutaneous (TRAM) flap is that there is a lower incidence of abdominal wall donor-site morbidity with the DIEP flap. However, venous congestion is the most dreaded complication of DIEP flap surgery which requires prompt intervention. In this case report, we present a simple but effective procedure to salvage the congested DIEP flap. A 55-year-old female underwent left breast reconstruction with DIEP flap and developed venous congestion during surgery. Cannula venesection of the superficial inferior epigastric vein (SIEV) was performed intraoperatively followed by intermittent aspiration of blood for 3 days. A satisfactory aesthetic result was achieved with no evidence of fat necrosis. This procedure eliminated the need for performing an additional microvascular anastomosis, required less operative time, and allowed augmentation of the venous drainage of the congested flap.

Level of Evidence: Level V, therapeutic study.
\end{abstract}

Keywords DIEP flap · Cannula · Venesection · SIEV · Venous congestion

Kongkrit Chaiyasate

kongkrit.chaiyasate@beaumont.edu

1 Division of Plastic surgery, Department of Surgery, Faculty of Medicine, Chiang Mai University, Chiang Mai, Thailand

2 Plastic \& Reconstructive Surgery Fellow, Department of Plastic and Reconstructive Surgery, Detroit Medical Center, Detroit, MI, USA

3 Department of Plastic Surgery, Beaumont Health System, Royal Oak, MI, USA

\section{Introduction}

The DIEP flap has proven to be a major advancement in autologous breast reconstruction. This flap has become a valuable option due to the small amount of rectus abdominis muscle fascia sacrificed causing less anterior abdominal wall morbidity such as hernia formation or bulging $[1,2]$. The arterial supply of the DIEP flap is not frequently compromised, but the flap has a potential venous drainage problem. While raising the flap, it is inevitable that many perforators must be sacrificed. In conjunction with transection of the superficial veins, venous insufficiency can result.

\section{Case report}

A 55-year-old female with a history of breast conservation surgery and radiation for left breast cancer presented 4 years postoperatively with a painful scar contraction deformity. She had remained cancer-free and had no other medical illness. See (Fig. 1) for the preoperative appearance of the patient. The patient's only previous abdominal surgery was a hysterectomy, but preoperative CT angiogram of the abdomen and pelvis confirmed the presence of adequate periumbilical perforators. The surgical plan was for the general surgeon to complete a left simple mastectomy in order to fully excise the scar tissue, then the plastic surgeon would perform immediate left breast reconstruction with a DIEP flap.

After left simple mastectomy was completed, immediate reconstruction of the left breast was performed with a rightsided DIEP flap that contained three perforators. The SIEV was harvested with the flap per the surgeon's routine. In this 
case, the SIEV was noted to be atypically moderately engorged immediately after division. Microvascular anastomosis was performed between the internal mammary artery and the deep inferior epigastric artery with 8-0 Nylon. Venous anastomosis was performed between the internal mammary vein and deep inferior epigastric vein with a 3.0-mm Flow Coupler (Synovis, Baxter International Inc, Alabama). Patency of the venous anastomosis without kinking was confirmed by direct inspection under the microscope, Acland (vessel strip) test, and audible flow on the implantable venous Doppler.

The flap was reperfused for approximately $20 \mathrm{~min}$, and the venous doppler signal was normal. However, the flap was noted to be congested, and the clipped SIEV was engorged significantly. Inspection of the vascular pedicles revealed that there was no kinking and that the caliber of each of the anastomosed vessels was normal. The clip on the superficial vein was removed, and high-flow venous blood spurted out. In order to relieve the venous congestion and avoid fat necrosis, there were two options. The first option was to supercharge the DIEP flap by performing a retrograde anastomosis of the SIEV with a vein graft to either the internal mammary vein or the thoracoacromial vein. The second option was cannula venesection which entailed placement of a catheter into the SIEV to allow intermittent phlebotomy to relieve the pressure of the venous congestion. We chose to perform cannula venesection of the SIEV because it would require less operative time than supercharging the flap, and it would avoid having to create another microanastomosis.Venesection of the SIEV entailed inserting the cannula (Surge cardiovascular, blunt tip without check value) into the SIEV lumen, tunneling it out of the skin of the anterior chest wall at

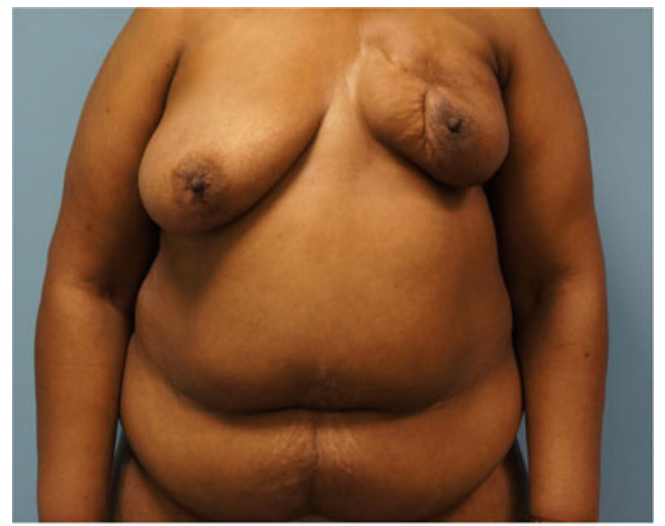

Fig. 1 Preoperative view of a 55-year-old female patient with a history of left breast conservation surgery, radiation, and a painful scar contraction deformity the inferomedial aspect of the reconstructed breast, and securing the cannula to the SIEV with 2-0 silk (Fig. 2). The cannula was secured to the skin with several interrupted 3-0 Prolene sutures. The three-way tap extension was kept open with heparinized saline. Venesection of the flap was performed by withdrawing $10 \mathrm{ml}$ of blood every $4 \mathrm{~h}$ on the first postoperative day, every $6 \mathrm{~h}$ on the second day, and every $8 \mathrm{~h}$ on the third day. After $72 \mathrm{~h}$ of intermittent venous drainage, the cannula was withdrawn. After $72 \mathrm{~h}$ of augmentation of venous drainage, the flap was less congested, and the cannula was withdrawn. The total amount of aspirated blood was $110 \mathrm{ml}$. Blood transfusion was not necessary in this case.

The flap remained viable with no evidence of fat necrosis. The patient was discharged on postoperative day 5 and was scheduled for revision surgery for symmetry 6 months postoperatively. An acceptable aesthetic result was achieved (Fig. 3).

\section{Discussion}

The venous anatomy of infraumbilical abdominal skin and subcutaneous tissue is variable in the DIEP flap elevation. The SIEV distributes deep branches which perforate through the anterior rectus sheath and drain into the venae comitantes of the deep inferior epigastric artery (DIEA). The small connection between this superficial and deep venous system is via the oscillating veins [3-5]. During harvest of the DIEP flap, these perforating veins are inevitably interrupted. If the remaining perforators are inadequate, flap congestion results. The incidence of venous congestion of the DIEP flap is $2-8 \%$, and it must be treated by venous augmentation to relieve the congestion and alleviate flap morbidity [6].

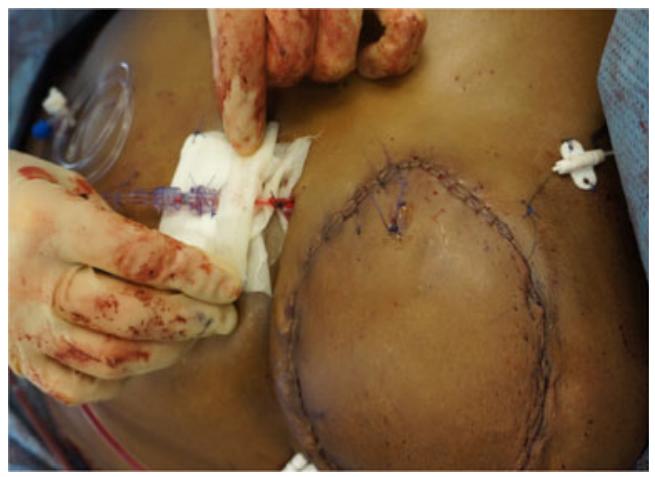

Fig. 2 Cannula venesection of SIEV was performed intraoperatively 


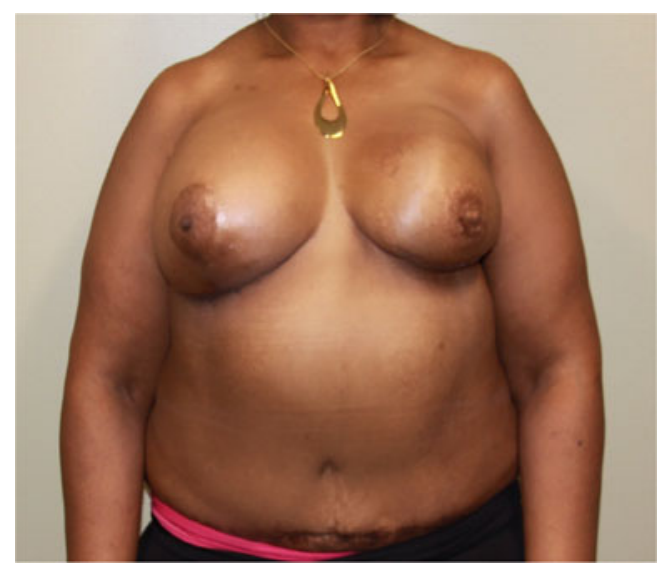

Fig. 3 Postoperative view at 6 months after revision surgery for symmetry

Several effective techniques to augment or supercharge the venous outflow of DIEP flap have been established $[6,7]$. The reports of the SIEV to the cephalic vein, thoracodorsal vein, lateral thoracic vein, basilic vein, DIEV, thoracoacromial vein, and proximal cut end of second DIEV venae comitantes have been well described [8-15].

The concept of venesection of the SIEV was proposed by Hartrampf CR Jr et al., Caplin DA, and Stasch [16-18]. Hartrampf et al. inserted the arteriotomy cannula into the lumen of DIEA and DIEV and used it as a mechanical leech. Intermittent venous bleeding from the DIEV allowed the congested flap time to improve venous outflow and adapt to the new reversed blood circulation. Stasch et al. reported the success of the venesection of the SIEV. They introduced the cannula connected with a three-way tap extension into the SIEV and aspirated blood every 4-6 $\mathrm{h}$.

After we noticed mild congestion of the flap and obvious engorgement of the SIEV, we decided to perform cannula venesection of the SIEV. It is a simple, quick procedure rather than the other microsurgical operative options. This procedure avoided further vessel dissection and the risk of additional microsurgical anastomosis. The total blood loss from the venesection in our case was only $110 \mathrm{ml}$, and blood transfusion was not needed.

Since the venous congestion in the DIEP flap is multifactorial, it is very important to meticulously dissect and preserve the total length of SIEV during the DIEP flap elevation. If the flap congestion is recognized, prompt augmentation of venous outflow is required. Cannula venesection of the SIEV is a safe, simple, and effective way to salvage the venous congested DIEP flap.

\section{Compliance with ethical standards}

Ethical standards For this type of study formal consent from an ethics committee is not required.

Conflict of interest Puttan Wongtriratanachai, Abbe Michelle Martin, Kongkrit Chaiyasate declare that they have no conflicts of interest.

Patient consent Patient provided written consent before her inclusion in this study. Additional consent was obtained for the use of her images.

Funding This study has not been funded.

Open Access This article is distributed under the terms of the Creative Commons Attribution 4.0 International License (http:// creativecommons.org/licenses/by/4.0/), which permits unrestricted use, distribution, and reproduction in any medium, provided you give appropriate credit to the original author(s) and the source, provide a link to the Creative Commons license, and indicate if changes were made.

\section{References}

1. Kaplan JL, Allen RJ (2000) Cost-based comparison between perforator flaps and TRAM flaps for breast reconstruction. Plast Reconstr Surg 105:943-8

2. Kroll SS, Sharma S, Koutz C et al (2001) Postoperative morphine requirements of free TRAM and DIEP flaps. Plast Reconstr Surg 107:338-41

3. Rozen WM, Pan WR, Le Roux CM, Taylor GI, Ashton MW (2009) The venous anatomy of the anterior abdominal wall: an anatomical and clinical study. Plast Reconstr Surg 124:848-53

4. Imanishi N, Nakajima H, Minabe T, Chang H, Aiso S (2003) Anatomical relationship between arteries and veins in the paraumbilical region. Br J Plast Surg 56:552-6

5. Blondeel PN, Arnstein M, Verstraete K et al (2000) Venous congestion and blood flow in free transverse rectus abdominis myocutaneous and deep inferior epigastric perforator flaps. Plast Reconstr Surg 106:1295-9

6. Ochoa O, Pisano S, Chrysopoulo M, Ledoux P, Arishita G, Nastala C (2013) Salvage of intraoperative deep inferior epigastric perforator flap venous congestion with augmentation of venous outflow: flap morbidity and review of the literature. Plast Reconstr Surg Glob Open 1:e52

7. Tran NV, Buchel EW, Convery PA (2007) Microvascular complications of DIEP flaps. Plast Reconstr Surg 119:1397-405, discussion 406-8

8. Ali R, Bernier C, Lin YT et al (2010) Surgical strategies to salvage the venous compromised deep inferior epigastric perforator flap. Ann Plast Surg 65:398-406

9. Liu TS, Ashiian P, Festekjian J (2007) Salvage of congested deep inferior epigastric perforator flap with a reverse flow venous anastomosis. Ann Plast Surg 59:214-7

10. Sbitany H, Mirzabeigi MN, Kovach SJ, Wu LC, Serletti JM (2012) Strategies for recognizing and managing intraoperative venous congestion in abdominally based autologous breast reconstruction. Plast Reconstr Surg 129:809-15 
11. Kerr-Valentic MA, Gottlieb LJ, Agarwal JP (2009) The retrograde limb of the internal mammary vein: an additional outflow option in DIEP flap breast reconstruction. Plast Reconstr Surg 124:717-21

12. Enajat M, Rozen WM, Whitaker IS, Smit JM, Acosta R (2010) A single center comparison of one versus two venous anastomoses in 564 consecutive DIEP flaps: investigating the effect on venous congestion and flap survival. Microsurgery 30:185-91

13. Momeni A, Lee GK (2010) A case of intraoperative venous congestion of the entire DIEP-flap-a novel salvage technique and review of the literature. Microsurgery 30:443-6

14. Guzzetti T, Thione A (2008) The basilic vein: an alternative drainage of DIEP flap in severe venous congestion. Microsurgery 28:555-8
15. Davies AJ, O'Neill JK, Wilson SM (2014) The superficial outsideflap shunt (SOS) technique for free deep inferior epigastric perforator flap salvage. J Plast Reconstr Aesthet Surg 67:1094-7

16. Hartrampf CR Jr, Drazan L, Noel RT (1993) A mechanical leech for transverse rectus abdominis musculocutaneous flaps. Ann Plast Surg 31:103-5

17. Caplin DA, Nathan CR, Couper SG (2000) Salvage of TRAM flaps with compromised venous outflow. Plast Reconstr Surg 106:400-1

18. Stasch T, Goon PK, Haywood RM, Sassoon EM (2009) DIEP flap rescue by venesection of the superficial epigastric vein. Ann Plast Surg 62:372-3 